\title{
BIR \\ INSTRUCTIONAL REVIEW - RESEARCH \\ The use of rats and mice as animal models in ex vivo bone growth and development studies
}

\section{A. A. Abubakar, M. M. Noordin, T. I. Azmi, U. Kaka, M. Y. Loqman}

Universiti Putra Malaysia, Malaysia

A. A. Abubakar, DVM, MVS, - U. Kaka, DVM, MSc, PhD, - M. Y. Loqman, DVM, MVM, PhD, Department of Companion Animal Medicine and Surgery, - M. M. Noordin, DVM, MSc, $\mathrm{PhD}$, Department of Veterinary Pathology and Microbiology, - T. I. Azmi, DVM, MSc, PhD, Department of Pre-Clinical Veterinary Sciences,

Universiti Putra Malaysia, Malaysia.

Correspondence should be sent to M. Y. Loqman;

email: loqman@upm.edu.my

doi: $10.1302 / 2046-3758.512$ BJR-2016-0102.R2

Bone Joint Res 2016;5:610-618. Received: 12 April 2016;

Accepted: 6 October 2016

In vivo animal experimentation has been one of the cornerstones of biological and biomedical research, particularly in the field of clinical medicine and pharmaceuticals. The conventional in vivo model system is invariably associated with high production costs and strict ethical considerations. These limitations led to the evolution of an ex vivo model system which partially or completely surmounted some of the constraints faced in an in vivo model system. The ex vivo rodent bone culture system has been used to elucidate the understanding of skeletal physiology and pathophysiology for more than 90 years. This review attempts to provide a brief summary of the historical evolution of the rodent bone culture system with emphasis on the strengths and limitations of the model. It encompasses the frequency of use of rats and mice for ex vivo bone studies, nutritional requirements in ex vivo bone growth and emerging developments and technologies. This compilation of information could assist researchers in the field of regenerative medicine and bone tissue engineering towards a better understanding of skeletal growth and development for application in general clinical medicine.

Cite this article: Bone Joint Res 2016;5:610-618.

Keywords: Rat, mouse, Ex vivo, Bone culture

\section{Introduction}

Globally, musculoskeletal disorders have a major influence on both the elderly human and animal. ${ }^{1}$ It was estimated that 150 different musculoskeletal disease conditions affect both human and animal populations. ${ }^{1,2}$ The most common conditions are those with greater economic impact, namely osteoarthritis, osteoporosis, rheumatoid arthritis, spinal disorders, limb trauma, gout, osteosarcoma, sprains and strains. ${ }^{3}$ In the United States alone, the estimated total cost of these musculoskeletal conditions amounts to $\$ 250$ billion annually. ${ }^{3}$ The prevalence of these conditions and their economic burden have been projected to increase in future, in light of the ageing population. ${ }^{4}$ There is thus a need for an in-depth investigation into the mechanism of and therapeutic measures for these conditions using different laboratory animal models.

In vivo and ex vivo animal studies have significantly contributed to numerous biomedical investigations into the discovery of drugs, clinical medicine, bone metabolism and morphological changes induced by mechanical loading of the bone. ${ }^{5,6}$ These research areas had largely used animal models for the development and enhancement of numerous existing clinical therapies which involved soft and hard tissues in human and veterinary medicine. ${ }^{7,8}$ In vivo animal model investigations are very costly and occasionally present with multiple challenges involving strict ethical considerations, problems associated with animal handling and alterations of normal physiological parameters due to fear and fright during experimental procedures. These challenges paved the way for multiple alternative ex vivo model systems.9,10 In many ways, the ex vivo model system mimics the conventional in vivo model as the tissues and cells are morphologically positioned in situ within the normal extracellular matrix. This makes the ex vivo models in many biomedical investigations mimic the in vivo system. ${ }^{11-13}$ Therefore, the ex vivo biology system could be a good substitute for some in vivo and in vitro models in an experimental design which is relatively cost effective and ethically acceptable in terms of animal welfare. ${ }^{14-16}$ 
Table I. Summary of research involving animal species other than avian and rodent for ex vivo bone culture for bone growth- and development-related investigations $\mathbf{s}^{12,23-35}$

\begin{tabular}{|c|c|c|}
\hline Species involved & Types of bone used & Source \\
\hline Canine & Cancellous bone & Rawlinson et $\mathrm{al}^{23}$ \\
\hline Bovine & Articular cartilage & Hall24 \\
\hline Ovine & Cancellous bone & Knothe Tate and Knothe ${ }^{25}$ \\
\hline Bovine & Trabecular bone & Smith et $\mathrm{al}^{26}$ \\
\hline Bovine & Articular cartilage & Bush and Hall27 \\
\hline Bovine & Articular cartilage & Bush and Hall28 \\
\hline Human & Trabecular bone & Smith et $\mathrm{al}^{29}$ \\
\hline Human, bovine and ovine & Trabecular bone & Davis et $\mathrm{al}^{30}$ \\
\hline Bovine & Trabecular bone & David et al ${ }^{12}$ \\
\hline Bovine & Articular cartilage & Amin et $\mathrm{al}^{31}$ \\
\hline Bovine & Wounded articular cartilage & Amin et $a^{32}$ \\
\hline Bovine & Articular cartilage & Otsuki et al33 \\
\hline Bovine & Trabecular bone & Vinaco et $\mathrm{al}^{34}$ \\
\hline Human & Cortical femoral bone & Templeton et al 35 \\
\hline
\end{tabular}

The majority of the ex vivo bone developmental studies are intended for human application and other mammalian species using an embryonic chick bone model. However, there is a growth and developmental difference between avian and mammalian bone which could raise doubts in the interpretation of the experimental results for clinical application. ${ }^{17}$ Farquharson and Jefferies, ${ }^{18}$ and Nowlan et al, ${ }^{19}$ reported that the secondary ossification centre of embryonic avian bone is absent before hatching, but does occur in mammalian fetal bone. The primary cartilage in fetal chick bones lacks vascular supply prior to mineralisation. ${ }^{20}$ Other discrepancies between avian and mammalian bones include mammalian growth plate thickness which is relatively constant due to uniform blood supply and rate of bone resorption, as opposed to the irregular thickness of avian bone which is attributed to the absence of vascular supply to the primary cartilage. ${ }^{18} \mathrm{In}$ addition, the chondrocyte zones in the growth plate of the embryonic chick are not arranged in an orderly fashion compared with those of the mammalian species. ${ }^{21}$ However, the cellular and molecular pathways of bone growth in the two species do occur in a similar manner. In view of these differences between bone growth in the two species, the use of avian embryonic chick bones for human and other mammals may raise doubt regarding its applicability. This review is a comprehensive attempt to report on the historical evolution of the rodent bone culture system, and on technologies that can assist researchers in the field of bone regenerative medicine and bone tissue engineering, and to understand the ex vivo skeletal growth and development of the model for application in general clinical medicine.

Evolution of the ex vivo bone culture system of bone growth. Numerous ex vivo models of bone growth and developments have been studied using different animal species, other than rodents. The majority of this research utilises pathogen-free chick embryos. ${ }^{17,22}$ Ex vivo bone growth models and development studies, other than embryonic avian and rodent models, are summarised in Table I. ${ }^{12,23-35}$

The use of postnatal bovine cancellous bone for an ex vivo model appeared to be more popular compared with avian and rodent models. This could be due to the fact that bovine bone has true bone lamellar structure similar to that of human bone, which enhances interpretation and application in human studies. Trabecular bone is more frequently used than cortical bone because the former is metabolically active. ${ }^{12}$

The utilisation of ex vivo bone tissue culture for the study of skeletal growth and development was reported about 90 years ago using an embryonic chick model. ${ }^{36,37}$ A subsequent study by Fell and Robinson ${ }^{36}$ encountered some challenges in that the culture media then had to be supplemented with embryonic extract, plasma or serum. Culture media with such supplements were difficult to reproduce because the supplements were usually not produced in their purest form and contained variable concentrations of undesirable substances such as hormones. It is also difficult to differentiate between the cancellous or cortical bone growth requirements, as they differ in terms of their chemical matrices and as such respond to environmental changes independently. ${ }^{12,17,14}$

The aforementioned challenges triggered many investigators to conduct series of studies, particularly in the area of ideal standard media required for optimal ex vivo bone growth. Since then, numerous investigations have been conducted utilising embryonic chick bone models for skeletal growth and development. ${ }^{21,38-44}$ In 1977, Messer ${ }^{45}$ introduced a continuous-flow system of culture in an attempt to overcome the challenge of metabolite accumulation encountered in the stationary system. However, the method was not popular, possibly due to difficulties in reproducing and maintaining the exact experimental protocol.

Previously it was thought that embryonic bone could only be cultured ex vivo for a maximum of 18 days prior 


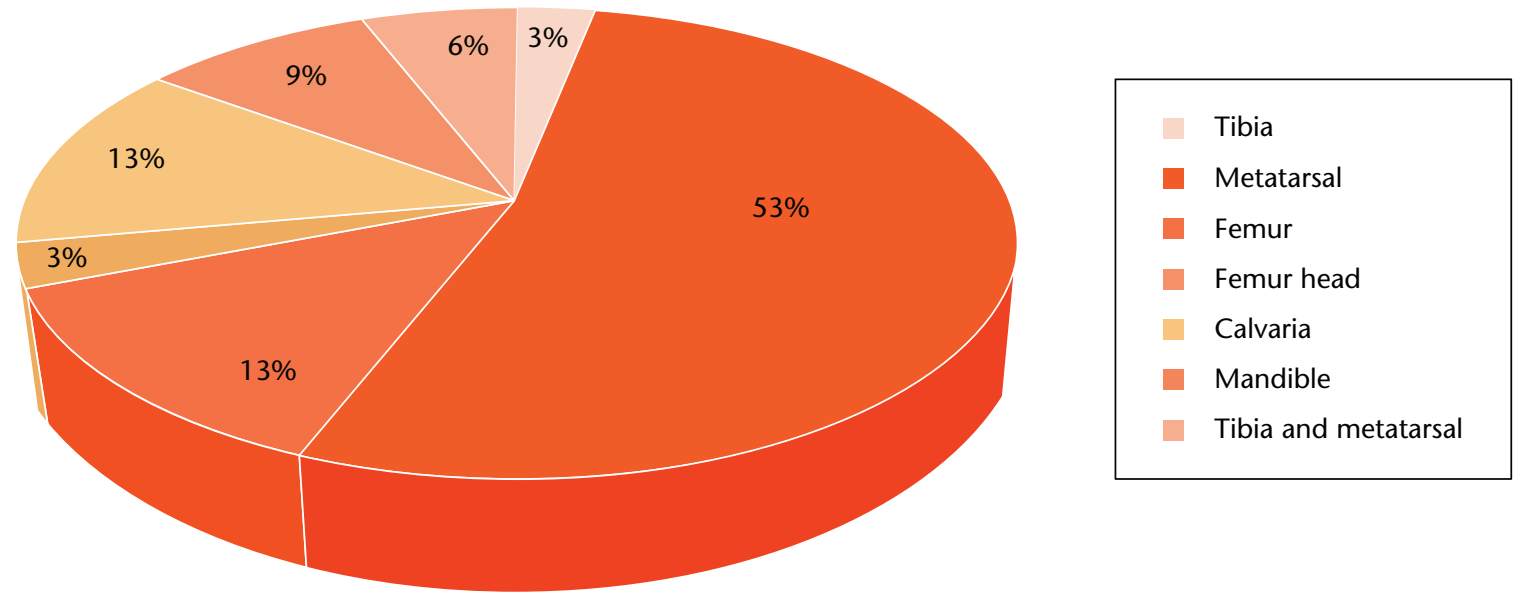

Fig. 1

Pie chart showing percentage distribution from the various species of rodent and the types of bones used for ex vivo bone growth studies based on the available studies published from 2000.

to bone tissue deterioration, based on the reported optimal culture period of ten to 18 days. ${ }^{17}$ However, recent work conducted by Chagin et al ${ }^{46}$ and Okubo et al ${ }^{47}$ revealed that the embryonic bone of rats and mice could be cultured ex vivo for a longer duration of up to five or six months with the bone tissue remaining viable.

Rat and mouse ex vivo model for bone growth studies. The use of rats and mice as a model of bone growth started around the early 1960 s, ${ }^{48,49}$ exploring bone physiology using embryonic rat forelimbs at 19 days of gestation (E19) and mouse calvaria from five-day-old (P5) postnatal mice. Ex vivo bone culture studies involving bone physiology and the effect of hormones on bone is now common. ${ }^{50,51}$ The early experiments documented only bone resorption, without evidence of bone formation. ${ }^{48,52-54}$ Subsequent studies conducted by Bingham and Raisz ${ }^{14}$ demonstrated that embryonic long bones of rats grew in length with evidence of new bone formation, which further showed that bone formation was influenced by the concentration of calcium, phosphate and magnesium ions in the culture media. This finding paves the way for numerous investigations into the nutritional requirements for optimal growth of bone in the ex vivo environment. Raisz ${ }^{48}$ used Eagle's medium for standard cell culture which was supplemented with human serum, while Goldhaber ${ }^{49}$ used Gey's balance salt solution supplemented with heated horse serum and chick embryo extract. Although the bones were cultured in a different microenvironment, successful physiological activities were demonstrated. Raisz ${ }^{48}$ incubated the embryonic bones in a humidified plastic chamber for 72 hours in $5 \% \mathrm{CO}_{2}, 20 \% \mathrm{O}_{2}$, and $75 \% \mathrm{~N}_{2}$ at $37^{\circ} \mathrm{C}$, while Goldhaber ${ }^{49}$ incubated the bones in a humidified stationary culture tube containing $95 \% \mathrm{O}_{2}$ with $5 \% \mathrm{CO}_{2}$ for 12 days. Following these findings, many researchers developed an interest in bone tissue-related research, focusing attention on skeletal growth and development with an emphasis on the pathophysiology of different skeletal disease conditions.
Previous studies used large containers such as petri dishes, stationary tubes and Leighton tubes to incubate the bone. ${ }^{14,48,49}$ The disadvantage of using petri dishes and tubes is that it requires a large volume of media to sufficiently cover the bones. Subsequent studies have overcome this by incubating the bone tissue in either sixor 24-well plates depending on the size of the bone intended to be cultured. ${ }^{44,55-64}$ Currently, some studies involving bone culture ex vivo focus on the use of a dynamic bioreactor and chorioallantoic membrane (CAM) culture system. ${ }^{22}$

Ex vivo model for consideration: rat versus mouse. Available research records that used rats and mice for ex vivo skeletal growth and development published since 2000 showed that both rats and mice have been equally used for ex vivo bone culture investigations. This could indicate that both species used for ex vivo bone culture studies probably give similar results when used as a model for bone growth. Other reasons that likely warrant the choice of either rat or mouse are the personal preference of the investigator or the protocol intended to be adopted. This trend could change in the future, with the possibility of a slight shift towards the use of more rat models. This is due to the advantage of the larger size of rat bones which can be easily dissected intact without morphological alteration of the bone structures. However, the murine model is gaining popularity because of the availability of genetic modification, i.e. the gene knockout model. With this in mind, the frequency of murine model usage may also likely be higher in comparison with that of rats in future investigations.

With regards to the type of bone used, available research shows that the metatarsal bone had the highest percentage $(53 \%)$ of use when compared with other bone types (Fig. 1). The exact reason for this frequent usage is not known but it could be associated with the small size of the bone which can be easily and 
conveniently cultured in relatively small culture plates. The other likely reason for the frequent use of metatarsal bone could be its greater numbers, i.e. five metatarsal bones per limb, which provides an adequate sample size for statistical analysis. The preference could also be attributed to the low degree of calcification in early postnatal life (days 1 to 7), ${ }^{65}$ which facilitates histological processing without the need for decalcification for intact in situ histomorphological studies.

The choice of calvaria and femoral bones each represent $13 \%$ of the published data (Fig. 1). The preference for the femur, following the metatarsal, could be due to the former providing a good model for endochondral bone formation. Nevertheless, this has a major disadvantage from the point of view of its large size, which may require a huge volume of growth media in a conventional static bone growth set-up. However, the femur is the preferred ex vivo model for breast cancer metastasis because it is considered to be highly susceptible to most softtissue cancer metastases. ${ }^{66,67}$ Stern and Krieger, 56 and Schwartz et al $^{66}$ reported that the choice of calvaria for ex vivo bone culture models provides an easy system for intramembranous bone growth. It also offers the additional advantage of providing enough material for a simple biochemical analysis. Recent studies conducted by Curtin et al ${ }^{68}$ and Krishnan et al ${ }^{69}$ also used neonatal and postnatal calvaria to study cancer metastasis.

Studies have also shown that the selection of neonatal and postnatal bones is almost equal to that of neonatal bone $(53.1 \%)$, which indicates that the two stages of rodent (embryonic and post-embryonic) development have almost equal preference in ex vivo skeletal growth and development studies. Earlier research, prior to 2000, showed more frequent use of embryonic bones compared with postnatal bones, ${ }^{17}$ The reason being that embryonic bone tissue has a higher capacity for bone growth and metabolic activities, as reported by Mohammad et al. ${ }^{70}$

Nutritional requirement of bone growth ex vivo. Early media used for in vitro cells and tissue growth were pieces of tissue explants, human or animal plasma or fibrinogen clots. The growing cells or tissues are attached to these biological substances. The media are supplemented with human placental serum, avian embryonic extracts or balanced salt solution. ${ }^{71}$ Currently, there is a wide variety of commercially available media that have been tested to support the growth of both embryonic and postnatal bones in an ex vivo microenvironment. Commercially available media contain a range of 25 to 29 macro nutrients components made up of 13 amino acids, seven vitamins, glucose, and seven different salts with different types of minerals that support the growth of bone ex vivo. ${ }^{72}$ The standard bone culture media are supplemented with various nutritional ingredients and antibiotics at the discretion of the researchers for optimal growth of bone and suppression of bacterial contaminants. Most commonly available supplements include bovine albumin and fetal calf serum, ascorbic acid, sodium glycerol phosphate, glutamine and many other supplements depending on the adopted protocol. Phenol red is usually added to the standard medium to indicate level of tissue utilisation and metabolic activities. The most widely used media for bone tissue culture include Dulbecco's modified Eagle medium (DMEM), alpha-minimum essential medium ( $\alpha$-MEM) and Biggers, Gwatkin and Judah $(B G J b)$ medium. The DMEM and BGJb are modifications of Basal Medium Eagle (BME) while $\alpha$-MEM is a modification of Harry Eagle's minimum essential medium (MEM or EMEM).

Current development in the field of bone culture systems. Currently, ex vivo bone growth and development can be assessed with the two latest models: the dynamic 3D bioreactor and the CAM culture system. The introduction of bioreactor techniques in animal experimentation has made it possible to conduct biomechanical force investigations within in vitro and ex vivo conditions. ${ }^{12,73-75}$ It was observed that culturing of whole bone in the dynamic 3D bioreactor can enhance tissue perfusion during ex vivo growth; ${ }^{12}$ this is achieved by ensuring uniform culture media perfusion into the bone tissue thereby permitting adequate delivery of nutrients into the bone core. The system also allows for the assessment of mechanical parameters of the cultured bone. Bone viability could be maintained for considerably longer with a maximum media perfusion flow rate of $6.6 \mathrm{mLh}^{-1}$ under controlled biochemical and mechanical conditions. ${ }^{34}$ The system permits monitoring of culture conditions such as $\mathrm{pH}$, temperature, and the supply of oxygen and carbon dioxide. The culture media need to be changed every 24 to 48 hours as in conventional static bone culture systems. ${ }^{30,34}$ One of the greatest advantages of the bioreactor for ex vivo bone culture, apart from improved culture media circulation, is the reduction in the number of handling steps, which may likely minimise potential contamination of the bone tissue. ${ }^{76}$

There are two types of bioreactors that are currently available for ex vivo bone culture, ${ }^{77}$ namely the rotating oxygen-diffusing vessels and magnetic force bioreactors. The rotating oxygen-diffusion system is usually filled with culture media and perfusion systems incorporated to control the back-and-forth flow within the system. It was reported by Partap et $\mathrm{al}^{78}$ and Rauh et $\mathrm{al}^{79}$ that the rotating oxygen-diffusion bioreactor system has an increased osteogenic cell multiplication capacity, and enhanced osteogenesis. In vitro-enhanced differentiation and maturation of human mesenchymal stromal cells to chondrocytes was also observed by Hoffmann et al. ${ }^{80}$ It was also reported that bone viability can be maintained for a longer duration which could translate to increased osteogenesis in cell-seeded bone when the rotating oxygen-diffusion 
system is combined with the compression bioreactor that applied mechanical force on the bone tissue. ${ }^{81-83}$ The magnetic force bioreactor applies forces directly to the cell membrane within the bone tissue, rather than to the surrounding bone scaffold. This task is accomplished by cell attachments to an in-built magnetic nanoparticle. ${ }^{84,85}$ The system can also enhance expression of bone extracellular matrix proteins, and osteogenic cell differentiation and their proliferation. ${ }^{76,86} \mathrm{It}$ can also mechanically stimulate mesenchymal cell-seeded bone scaffolds, osteogenic cells and whole bone explants. ${ }^{87-90}$

Currently only human, bovine and ovine trabecular bones have been cultured using the dynamic bioreactor system in studies investigating the biomechanics of cancellous bone during growth, remodeling and modeling investigation trials. ${ }^{12,85}$ Bioreactor technologies are yet to be fully adopted for use in rodent ex vivo bone culture. If adopted for bone growth and development, it may enable application of the ex vivo tissue culture system to be a closer approximation of the in vivo model outside the living environment. However, the utilisation of a bioreactor system has been initiated for the ex vivo culture of avian bone; a study was conducted by Henstock et al ${ }^{91}$ using a customised bioreactor system that was developed mainly for culturing an embryonic chick femur. The results showed an increase in bone growth and mineralisation.

The CAM culture system is a new modification of the ex vivo tissues/organ culture system. ${ }^{92-97}$ The model uses a minimum 72-hour-old embryonic egg in which a small window is made on the shell surface into the CAM. The tissue to be cultured will then be inoculated directly on the CAM next to the developing chick embryo. ${ }^{95}$ The ex vivo/ex ovo culture system was found to be very useful for studies involving avian, human and rodent tissues in diverse fields of scientific investigation ranging from tissue angiogenesis, ${ }^{98-101}$ anti-angiogenesis, ${ }^{98,102}$ oncology, ${ }^{103-106}$ obstetrics, ${ }^{96,107,108}$ pharmaceuticals, ${ }^{95,109,110}$ bone development, ${ }^{111}$ imaging, ${ }^{109,112}$ microsurgery, ${ }^{112}$ culturing of xenotransplanted tissues and other biomedical applications. ${ }^{108,113}$ In the area of bone tissue engineering research, the CAM system was successfully used to investigate tissue neovascularisation during bone graft, regeneration and critical bone size defect studies. ${ }^{114-116}$ The CAM ex vivo culture systems have advantages over conventional static ex vivo systems of tissue culturing. The extra-embryonic membrane system has the capability to mediate oxygen and nutrient exchange within the chick embryo. The system was reported to be highly vascularised in such a way that it can be easily connected with the vascular network of implanted tissue. Above all, the model allows exogenous materials from other species to be implanted without immunogenic rejection as the embryonic chick immunity is usually not fully developed to challenge foreign bodies. ${ }^{116-118}$ To date, the use of the CAM model system is grossly under used in rodent ex vivo bone culture investigations. If the CAM model is applied with meticulous care, it would go a long way to provide an alternative that is a simple, reliable and inexpensive ex vivo bone culture system. Recently, the CAM model has been used for chick bone culture studies. ${ }^{17}$ The major drawback of the system is that ex vivo cultures cannot be carried out for a longer duration more than 15 to 18 days, as chick embryos develop within a limited period of approximately 21 days.

Reliability of the three ex vivo bone culture models. The 3D dynamic bioreactor bone organ culture was introduced for bone engineering applications to overcome challenges that were associated with conventional static bone culture systems. It was demonstrated to have improved distribution and to facilitate osteogenic cell maturation, ${ }^{119}$ but the majority of the bioreactor systems for bone engineering at present were designed with a low volume output. Additionally, their assembly is usually time-consuming and may exhibit operator-dependent variability. Therefore, the conventional static ex vivo bone culture is still considered the most practicable, reliable, easy and inexpensive means of in vitro growth of rodent bone for study involving osteogenic cell behaviour in a controlled environment.

Generally, the reliability of all the ex vivo tissue/organ cultures depends on the provision of a conducive physiological atmosphere that replicates the normal body condition of the explants in an intact organism. Therefore, the reliability of the conventional static ex vivo bone culture model and that of the dynamic 3D bioreactor model depend on the ability of the osteogenic cells to be in the appropriate extracellular matrix (ECM) compartment of the bone tissue microenvironment and retain viability and metabolic activity

The ECM is one of the important components of the bone tissue microenvironment because its presence is valuable for the maintenance of the physiological function of osteogenic cell polarisation, survival and proliferation. ${ }^{120}$ The whole bone tissue should be able to remain viable and continue to grow in the ex vivo culture environment for a minimum incubation period of 48 hours in a static culture system. In the 3D dynamic bioreactor system, bone cells should be able to maintain viability for an incubation period of at least 21 days. ${ }^{34}$ The metabolic activity of osteogenic cells are measured by their mineral deposits, therefore measurable mineral apposition should be recorded similar to the in vivo response at different ages and specific to the species of the animal model used.

In addition to cell viability, for the bioreactor bone organ culture to be reliable, the cultured bone must be able to demonstrate a response to a mechanical stimulus. ${ }^{121}$ In order to achieve reasonable growth of the whole bone in the dynamic bioreactor system, the osteogenic cells must undergo mechanical loading stimuli similar to those obtained in an in vivo scenario, as it was reported 


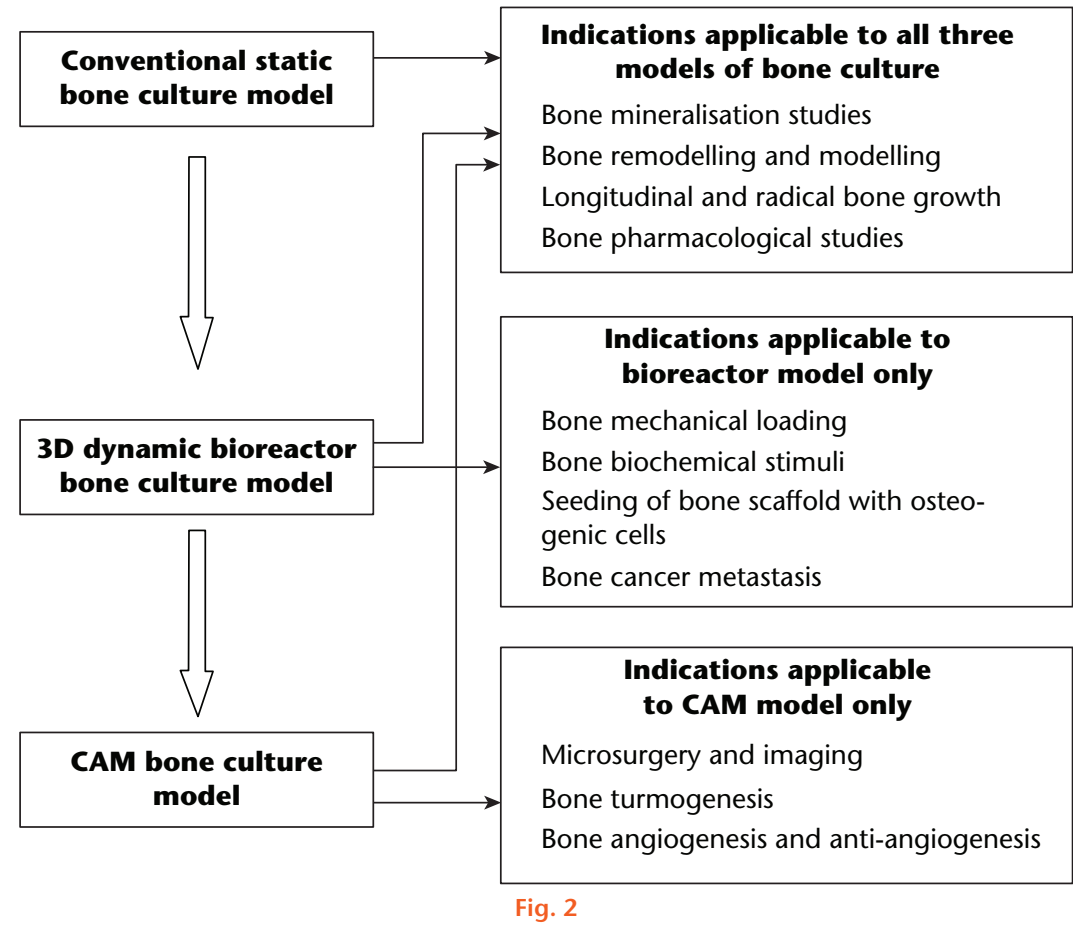

Order of preclinical application of the ex vivo rodent bone culture models and their indications in bone growth, development and related fields of studies. Note that all indications that are applicable for the conventional static culture system are equally applicable to other models. The block arrows indicate the current order of the mostly used technique (from top to bottom) among the three ex vivo models reported (CAM, chorioallantoic membrane).

that during locomotion in vivo, the bone cells are believed to undergo oscillatory and pulsatile flow. ${ }^{78}$

In order to maintain osteogenic cell viability, all of the bioreactor types for ex vivo bone culture were designed to function based on forced media flow around the bone tissue to provide nutrient delivery deep into the bone core beyond the periosteal bone surfaces, increase oxygenation within the construct, and eliminate the metabolic waste accumulated within the system. ${ }^{79}$ The fluid flow within the bioreactor system has also been shown to mechanically stimulate bone formation by increasing the osteogenic formation markers as reported by Batra et al, ${ }^{122}$ Kreke et al, ${ }^{123}$ and Jaasma and O'Brien. ${ }^{121}$ The formation of the osteogenic markers was also reported to improve bone mineralisation, which could lead to increased mechanical strength of the bone. ${ }^{124}$ It was also reported by Jaasma and $\mathrm{O}^{\prime}$ Brien $^{121}$ that whole bone tissue cultured in a continuous low flow rate medium of $0.01 \mathrm{~mL} /$ minute resulted in a high proportion of viable bone cells and an enhanced osteogenic response with improved spatial distribution of osteogenic cells when compared with the static culture method.

The overall survival rate of the chick embryo in either the in ovo or ex ovo technique is the major concern in the CAM ex vivo organ culture system. Therefore, an appropriate conducive incubation environment is the first priority, followed by a strict aseptic procedure devoid of microbial contaminants in order to reduce the level of environmental contamination to the bare minimum..$^{98}$ It has been reported that about $25 \%$ to $50 \%$ of the chick embryos die after manipulation of the egg. ${ }^{103,110}$

The reliability of the CAM ex vivo organ culture depends largely on the formation of new vascular networks in the implanted tissue, which may occur within a minimum of 48 hours after culture as reported by Dohle et al. ${ }^{94}$ The neovascular anastomosis can be checked and confirmed by various image analyses at different intervals during the incubation period. Quantitative vascular density can be evaluated using vesicular endothelial proliferation techniques..$^{99}$

Strength, indications and limitation of ex vivo bone culture models. The rodent ex vivo model system for bone growth has contributed significantly to scientific progress in the fields of developmental biology, genetics, cancer biology, cell biology and tissue engineering. The rapid development of rat and mouse skeletal tissue adaptation for ex vivo culture has become almost as popular as the avian model system which is extensively used in the field of skeletal biology studies. ${ }^{8}$ The ex vivo culture system is relatively cost-considerate; easily manipulated, and rapidly develops multiple cell types in their natural matrix. ${ }^{64}$

At present, the conventional static bone culture model is still the most widely used system for ex vivo bone culture for preclinical investigations in the field of musculoskeletal investigations. The order of most commonly reported models as discussed in this review is shown in Figure 2. The three different models are indicated for different fields of bone growth and developmental studies, 
but there are common indications that are applicable for all models. The 3D bioreactor model appears to have wider applications, whereas the conventional static bone culture model has the most limited research applications.

The conventional static and the 3D bioreactor bone culture models have disadvantages such as deficiency of blood supply to the ex vivo setup which remains a serious setback, since angiogenesis is critical for nutrient supply within the bone tissue. ${ }^{125-128}$ On the other hand, the lack of blood supply provides a unique opportunity to study cartilage and bone development and formation without being complicated by the vasculature. ${ }^{129-130}$

In conclusion, the rodent ex vivo bone culture system has great research potential in diverse medical fields. The system can be useful in understanding the complex biological events during bone growth development and fracture healing. It also provides a simple, inexpensive screening model with limited ethical considerations, and it addresses the issues of reduction, refinement and replacement ( $3 \mathrm{Rs}$ ) in an animal experimental system. These advantages of the rodent ex vivo model over conventional in vitro and in vivo, along with the developments of the dynamic bioreactor for ex vivo and CAM culture systems, will further enhance and improve the model. This also indicates that the ex vivo bone growth model will continue to provide a significant role in the growing field of skeletal growth and development in future.

\section{References}

1. Lidgren $\mathbf{L}$. The Bone and Joint Decade and the global economic and healthcare burden of musculoskeletal disease. J Rheumatol Supp/2003;67:4-5.

2. Woolf AD, Pfleger B. Burden of major musculoskeletal conditions. Bull World Health Organ 2003;81:646-656

3. No authors listed. Bone health and osteoporosis: a report of the Surgeon General. https://www.ncbi.nlm.nih.gov/books/NBK45513/(date last accessed 25 October 2016).

4. Symmons D, Mathers C, Pfleger B. The global burden of rheumatoid arthritis in the year 2000. http://www.who.int/healthinfo/statistics/bod_rheumatoidarthritis.pdf (date last accessed 25 November 2016).

5. Wood MW, Hart LA. Selecting appropriate animal models and strains: making the best use of research, information and outreach. AATEX 2007;14:303-306.

6. Kojima H. The use of 3-D models as alternatives to animal testing. Altern Lab Anim 2015; 43:40-43.

7. Zhang D, Luo G, Ding X, Lu C. Preclinical experimental models of drug metabolism and disposition in drug discovery and development. Acta Pharm Sin B 2012;2:549561.

8. Denayer T, Stöhrn T, Van Roy M. Animal models in translational medicine: validation and prediction. New Horiz Trans/ Med 2014;2:5-11.

9. Doke SK, Dhawale SC. Alternatives to animal testing: A review. Saudi Pharm $J$ 2015;23:223-229.

10. Graham ML, Prescott MJ. The multifactorial role of the $3 R$ s in shifting the harmbenefit analysis in animal models of disease. Eur J Pharmacol 2015;759:19-29.

11. Jos VS, Jones D, Richards RG, et al. Culture system for bone metabolic studies. Microgravity Applications Programme; 2005:306-315.

12. David V, Guignandon A, Martin A, et al. Ex Vivo bone formation in bovine trabecular bone cultured in a dynamic 3D bioreactor is enhanced by compressive mechanical strain. Tissue Eng Part A 2008;14:117-126.

13. Pearce Al, Richards RG, Milz S, Schneider E, Pearce SG. Animal models for implant biomaterial research in bone: a review. Eur Cell Mater 2007;13:1-10.

14. Bingham PJ, Raisz LG. Bone growth in organ culture: effects of phosphate and other nutrients on bone and cartilage. Calcif Tissue Res 1974;14:31-48.
15. Soskolne WA, Schwartz Z, Ornoy A. The development of fetal mice long bones in vitro: an assay of bone modeling. Bone 1986;7:41-48.

16. Colombo JS, Howard-Jones RA, Young FI, et al. A $3 D$ ex vivo mandible slice system for longitudinal culturing of transplanted dental pulp progenitor cells. Cytometry A 2015;87:921-928.

17. Smith EL, Kanczler JM, Oreffo ROC. A new take on an old story: chick limb organ culture for skeletal niche development and regenerative medicine evaluation. Eur Cell Mater 2013;26:91-106.

18. Farquharson C, Jefferies D. Chondrocytes and longitudinal bone growth: the development of tibial dyschondroplasia. Poult Sci 2000;79:994-1004

19. Nowlan NC, Murphy P, Prendergast PJ. Mechanobiology of embryonic limb development. Ann N Y Acad Sci 2007;1101:389-411.

20. Orth MW, Peters TL, Chlebek-Brown KA. Cartilage turnover in embryonic chick tibial explant cultures. Poult Sci 2000;79:990-993.

21. Roach HI. New aspects of endochondral ossification in the chick: chondrocyte apoptosis, bone formation by former chondrocytes, and acid phosphatase activity in the endochondral bone matrix. J Bone Miner Res 1997;12:795-805.

22. Smith EL, Kanczler JM, Gothard D, et al. Evaluation of skeletal tissue repair, part 1: assessment of novel growth-factor-releasing hydrogels in an ex vivo chick femur defect model. Acta Biomater 2014;10:4186-4196

23. Rawlinson SC, el-Haj AJ, Minter SL, et al. Loading-related increases in prostaglandin production in cores of adult canine cancellous bone in vitro: a role for prostacyclin in adaptive bone remodeling? J Bone Miner Res 1991;6:1345-1351.

24. Hall AC. Volume-sensitive taurine transport in bovine articular chondrocytes. J Physiol 1995; 484:755-766

25. Knothe Tate ML, Knothe U. An ex vivo model to study transport processes and fluid flow in loaded bone. J Biomech 2000;33:247-254

26. Smith EL, Martens F, Koller K, Clark W, Jones DB. The effects of 20 Days of mechanical loading plus PTH on the E-modulus of cow trabecular bone [abstract]. 22nd Annual Meeting of ASBMR, 2000

27. Bush PG, Hall AC. Regulatory volume decrease (RVD) by isolated and in situ bovine articular chondrocytes. J Cell Physio/ 2001;187:304-314.

28. Bush PG, Hall AC. The osmotic sensitivity of isolated and in situ bovine articular chondrocytes. J Orthop Res 2001;19:768-778.

29. Smith EL, Boudriot U, Daume B, et al. Long term perfusion loading of trabecular bone cores and formation rate. Eur Cell Mater 2003;5:48.

30. Davies CM, Jones DB, Stoddart MJ, et al. Mechanically loaded ex vivo bone culture system 'Zetos': systems and culture preparation. Eur Cell Mater 2006;11:57-75.

31. Amin AK, Huntley JS, Bush PG, et al. Chondrocyte death in mechanically injured articular cartilage-the influence of extracellular calcium. J Orthop Res 2009;27:778784.

32. Amin AK, Huntley JS, Bush PG, Simpson AH, Hall AC. Osmolarity influences chondrocyte death in wounded articular cartilage. J Bone Joint Surg [Am] 2008;90A:1531-1542.

33. Otsuki S, Grogan SP, Miyaki S, et al. Tissue neogenesis and STR0-1 expression in immature and mature articular cartilage. J Orthop Res 2010;28:96-102.

34. Vivanco J, Garcia S, Ploeg HL, et al. Apparent elastic modulus of ex vivo trabecular bovine bone increases with dynamic loading. Proc Inst Mech Eng H 2013;227:904-912.

35. Templeton ZS, Bachmann MH, Alluri RV, et al. Methods for culturing human femur tissue explants to study breast cancer cell colonization of the metastatic niche. J Vis Exp 2015;97:e52656.

36. Fell HB, Robison R. The growth, development and phosphatase activity of embryonic avian femora and limb-buds cultivated in vitro. Biochem J 1929;23:767-784.

37. Fell HB. Biochemistry and physiology of bone. Bource GH; New York Academic Press, ed. 1956:402

38. Hall BK. Intracellular and extracellular control of the differentiation of cartilage and bone. Histochem J 1981;13:599-614.

39. Roach HI. Long-term organ culture of embryonic chick femora: a system for investigating bone and cartilage formation at an intermediate level of organization. J Bone Miner Res 1990;5:85-100.

40. Roach HI. Induction of normal and dystrophic mineralization by glycerophosphates in long-term bone organ culture. Calcif Tissue Int 1992;50:553-563.

41. Roach HI. Trans-differentiation of hypertrophic chondrocytes into cells capable of producing a mineralized bone matrix. Bone Miner 1992;19:1-20.

42. Roach HI, Erenpreisa J, Aigner T. Osteogenic differentiation of hypertrophic chondrocytes involves asymmetric cell divisions and apoptosis. J Cell Biol 1995;131:483-494

43. Kanczler JM, Smith EL, Roberts CA, Oreffo ROC. A novel approach for studying the temporal modulation of embryonic skeletal development using 
organotypic bone cultures and microcomputed tomography. Tissue Eng Part C Methods 2012;18:747-760.

44. Smith EL, Rashidi H, Kanczler JM, Shakesheff KM, Oreffo ROC. The effects of $1 \alpha, 25-$ dihydroxyvitamin D3 and transforming growth factor- $\beta 3$ on bone development in an ex vivo organotypic culture system of embryonic chick femora. PLoS One 2015; 10:e0121653

45. Messer HH. Hormonal responses of bone in a continuous flow cultural system. J Dent Res 1977;56:971-975.

46. Chagin AS, Karimian E, Sundström K, Eriksson E, Sävendahl L. Catch-up growth after dexamethasone withdrawal occurs in cultured postnatal rat metatarsal bones. J Endocrino/ 2010;204:21-29.

47. Okubo N, Minami Y, Fujiwara H, et al. Prolonged bioluminescence monitoring in mouse ex vivo bone culture revealed persistent circadian rhythms in articular cartilages and growth plates. PLoS One 2013;8:e78306.

48. Raisz LG. Bone Resorption in tissue culture factors influencingthe response to parathyroid hormone. J Clin Invest 1965;44:103-116.

49. Goldhaber P. Remodeling of bone in tissue culture. J Dent Res 1966;45:490-499.

50. Richards RG, Simpson AE, Jaehn K, Furlong PI, Stoddart MJ. Establishing a $3 \mathrm{D}$ ex vivo culture system for investigations of bone metabolism and biomaterial interactions. ALTEX 2007;24:56-59.

51. Smith EL, Kanczler JM, Roberts CA, Oreffo ROC. Developmental cues for bone formation from parathyroid hormone and parathyroid hormone-related protein in an ex vivo organotypic culture system of embryonic chick femora. Tissue Eng Part C Methods 2012;18:984-994

52. Gaillard PJ. Growth and differentiation of explanted tissues. Int Rev Cytol 1953:2:331-401.

53. Raisz LG, Niemann I. Effect of phosphate, calcium and magnesium on bone resorption and hormonal responses in tissue culture. Endocrinology 1969;85:446-452.

54. Zanelli JM, Lea DJ, Nisbet JA. A bioassay method in vitro for parathyroid hormone. J Endocrino/ 1969;43:33-46.

55. Houghton GR, Dekel S. The periosteal control of long bone growth. An experimental study in the rat. Acta Orthop Scand 1979;50:635-637.

56. Stern PH, Krieger NS. Comparison of fetal rat limb bones and neonatal mouse calvaria: effects of parathyroid hormone and 1,25-dihydroxyvitamin D3. Calcif Tissue Int 1983:35:172-176

57. Lorenzo JA, Raisz LG, Hock JM. DNA synthesis is not necessary for osteoclastic responses to parathyroid hormone in cultured fetal rat long bones. J Clin Invest 1983;72:1924-1929.

58. Lorenzo JA, Holtrop ME, Raisz LG. Effects of phosphate on calcium release, lysosomal enzyme activity in the medium, and osteoclast morphometry in cultured fetal rat bones. Metab Bone Dis Relat Res 1984;5:187-190.

59. Pfeilschifter J, Mundy GR. Modulation of type beta transforming growth factor activity in bone cultures by osteotropic hormones. Proc Natl Acad Sci U S A 1987;84:2024-2028.

60. Pfeilschifter J, Seyedin SM, Mundy GR. Transforming growth factor beta inhibits bone resorption in fetal rat long bone cultures. J Clin Invest 1988;82:680-685

61. Harada $\mathbf{M}$, Miyahara $\mathbf{T}$, Miyata $\mathbf{M}$, et al. Effects on cultured neonatal mouse calvaria of $1 \alpha, 25$-dihydroxyvitamin D3, 26,26,26,27,27,27-hexafluoro-1 $\alpha, 25$ dihydroxyvitamin D3 and 26,26,26,27,27,27-hexafluoro-1 $\alpha, 23 S, 25$-trihydroxyvitamin D3. Bone Miner 1992;18:41-49.

62. Wu S, De Luca F. Role of cholesterol in the regulation of growth plate chondrogenesis and longitudinal bone growth. J Biol Chem 2004;279:4642-4647

63. Chagin AS, Karimian E, Zaman F, et al. Tamoxifen induces permanent growth arrest through selective induction of apoptosis in growth plate chondrocytes in cultured rat metatarsal bones. Bone 2007:40:1415-1424

64. Smith EL, Locke M, Waddington RJ, Sloan AJ. An ex vivo rodent mandible culture model for bone repair. Tissue Eng Part C Methods 2010;16:1287-1296.

65. Loqman MY, Bush PG, Farquharson C, Hall AC. Suppression of mammalian bone growth by membrane transport inhibitors. J Cell Biochem 2013;114:658-668.

66. Schwartz Z, Ornoy A, Soskolne WA. An in vitro assay of bone develop ment using fetal long bones of mice: morphological studies. Acta Anat (Basel) 1985;124:197-205

67. Sosnoski DM, Krishnan V, Kraemer WJ, Dunn-Lewis C, Mastro AM. Changes in cytokines of the bone microenvironment during breast cancer metastasis. Int $J$ Breast Cancer 2012;2012:160265

68. Curtin P, Youm H, Salih E. Three-dimensional cancer-bone metastasis mode using ex-vivo co-cultures of live calvarial bones and cancer cells. Biomaterials 2012;33:1065-1078

69. Krishnan V, Vogler EA, Sosnoski DM, Mastro AM. In vitro mimics of bone remodeling and the vicious cycle of cancer in bone. J Cell Physio/ 2014;229:453-462.
70. Mohammad KS, Chirgwin JM, Guise TA. Assessing new bone formation in neonatal calvarial organ cultures. Methods Mol Biol 2008;455:37-50.

71. Eagle H. Nutrition needs of mammalian cells in tissue culture. Science 1955;122:501 514

72. Lynch RG. Tissue culture of mammalian cells. ASIP Pathway 2008;3:31.

73. El Haj AJ, Cartmell H. Bioreactors for bone tissue engineering. Proc Inst Mech Eng H J Eng Med 2010;224:1523-1532.

74. Bilodeau K, Mantovani D. Bioreactors for tissue engineering: focus on mechanical constraints. A comparative review. Tissue Eng 2006;12:2367-2383.

75. Yu X, Botchwey EA, Levine EM, Pollack SR, Laurencin CT. Bioreactor-based bone tissue engineering: the influence of dynamic flow on osteoblast phenotypic ex pression and matrix mineralization. Proc Natl Acad Sci U S A 2004;101:11203-11208.

76. Gaspar DA, Gomide V, Monteiro FJ. The role of perfusion bioreactors in bone tis sue engineering. Biomatter 2012;2:167-175.

77. Salehi-Nik N, Amoabediny G, Pouran B, et al. Engineering parameters in bioreactor's design: a critical aspect in tissue engineering. Biomed Res Int 2013;2013:762132

78. Partap S, Plunkett NA, O'Brien FJ. Bioreactors in tissue engineering, tissue engineering. InTech 2010 http://www.intechopen.com/books/tissue-engineering/ bioreactors-in-tissue-engineering (date last accessed 11 October 2016).

79. Rauh J, Milan F, Günther KP, Stiehler M. Bioreactor systems for bone tissue engineering. Tissue Eng Part B Rev 2011:17:263-280.

80. Hoffmann W, Feliciano S, Martin I, de Wild M, Wendt D. Novel perfused compression bioreactor system as an in vitro model to investigate fracture healing. Front Bioeng Biotechnol 2015;3:10.

81. Pound JC, Green DW, Chaudhuri JB, Roach HI, Oreffo ROC. Bioreactor culture of cartilage from mesenchymal populations. J Bone Joint Surg [Br]2006;88-B:405

82. Bölgen N, Yang $\mathbf{Y}$, Korkusuz $\mathbf{P}$, et al. Three-dimensional ingrowth of bone cells within biodegradable cryogel scaffolds in bioreactors at different regimes. Tissue Eng Part A 2008;14:1743-1750.

83. Milan JL, Planell JA, Lacroix D. Computational modelling of the mechanical environment of osteogenesis within a polylactic acid-calcium phosphate glass scaffold. Biomaterials 2009;30:4219-4226.

84. Carpentier B, Layrolle P, Legallais C. Bioreactors for bone tissue engineering. Int J Artif Organs 2011;34:259-270.

85. Sladkova M, de Peppo GM. Bioreactor systems for human bone tissue engineering martina. Processes 2014;2:494-525.

86. Kleinhans C, Mohan RR, Vacun G, et al. A perfusion bioreactor system efficiently generates cell-loaded bone substitute materials for addressing critical size bone defects. Biotechnol J 2015;10:1727-1738.

87. Dobson J, Cartmell SH, Keramane A, El Haj AJ. Principles and design of a nove magnetic force mechanical conditioning bioreactor for tissue engineering, stem cel conditioning, and dynamic in vitro screening. IEEE Trans Nanobioscience 2006;5:173177

88. Hughes S, Dobson J, El Haj AJ. Magnetic targeting of mechanosensors in bone cells for tissue engineering applications. J Biomech 2007;40:S96-S104.

89. Fröhlich M, Grayson WL, Wan Lo, et al. Tissue engineered bone grafts: biological requirements, tissue culture and clinical relevance. Curr Stem Cell Res Ther 2008;3:254-264

90. Bock N, Riminucci A, Dionigi C, et al. A novel route in bone tissue engineering magnetic biomimetic scaffolds. Acta Biomater 2010:6:786-796.

91. Henstock JR, Rotherham M, Rose JB, El Haj AJ. Cyclic hydrostatic pressure stimulates enhanced bone development in the foetal chick femur in vitro. Bone 2013;53:468-477.

92. Salem AK, Rose FRAJ, Oreffo ROC, et al. Porous polymer and cell composites that self-assemble in situ. Adv Mater 2003;15:210-213

93. Green D, Walsh D, Yang X, Mann S, Oreffo ROC. Stimulation of human bone marrow stromal cells using growth Factor encapsulated calcium carbonate porous microspheres. J Mater Chem 2004;14:2206-2212.

94. Dohle DS, Pasa SD, Gustmann S, et al. Chick ex ovo culture and ex ovo CAM assay: how it really works. J Vis Exp 2009;33:e1620.

95. Yang XB, Whitaker MJ, Sebald W, et al. Human osteoprogenitor bone formation using encapsulated bone morphogenetic protein 2 in porous polymer scaffolds. Tissue Eng 2004:10:1037-1045

96. Isachenko V, Mallmann P, Petrunkina AM, et al. Comparison of in vitro- and chorioallantoic membrane (CAM)-culture systems for cryopreserved medulla-contained human ovarian tissue. PLoS One 2012;7:e32549.

97. Lokman NA, Elder ASF, Ricciardelli C, Oehler MK. Chick chorioallantoic membrane (CAM) assay as an in vivo model to study the effect of newly identified molecules on ovarian cancer invasion and metastasis. Int J Mol Sci 2012;13:9959-9970. 
98. Ribatti D, Nico B, Vacca A, Presta M. The gelatin sponge-chorioallantoic membrane assay. Nat Protoc 2006;1:85-91.

99. Deryugina El, Quigley JP. Chapter 2. Chick embryo chorioallantoic membrane models to quantify angiogenesis induced by inflammatory and tumor cells or purified effector molecules. Methods Enzymol 2008;444:21-41.

100. Feflea S, Cimpean AM, Ceausu RA, Gaje P, Raica M. Effects of antibodies to EG-VEGF on angiogenesis in the chick embryo chorioallantoic membrane. In Vivo 2012;26:793-797.

101. Chen $\mathbf{Z}$, Wen $\mathbf{Z}$, Bai $\mathbf{X}$. In vivo chick chrioallantoic membrane (CAM) angiogenesis assays. Bio Protoc 2013:3:e193.

102. Ribatti $\mathbf{D}$. The chick embryo chorioallantoic membrane as an in vivo assay to study antiangiogenesis. Pharmaceuticals (Basel) 2010;3:482-513

103. Balke M, Neumann A, Kersting C, et al. Morphologic characterization of osteosarcoma growth on the chick chorioallantoic membrane. BMC Res Notes 2010;3:58.

104. Sys G, Van Bockstal M, Forsyth R, et al. Tumor grafts derived from sarcoma patients retain tumor morphology, viability, and invasion potential and indicate disease outcomes in the chick chorioallantoic membrane model. Cancer Lett 2012;326:69-78.

105. Zabielska K, Lechowski R, Król M, et al. Derivation of feline vaccine-associated fibrosarcoma cell line and its growth on chick embryo chorioallantoic membrane - a new in vivo model for veterinary oncological studies. Vet Res Commun 2012;36:227-233.

106. Manjunathan $\mathbf{R}$, Ragunathan $\mathbf{M}$. Chicken chorioallantoic membrane as a reliable model to evaluate osteosarcoma-an experimental approach using SaOS2 cell line. Biol Proced Online 2015;17:10.

107. Malik E, Meyhöfer-Malik A, Berg C, et al. Fluorescence diagnosis of endometriosis on the chorioallantoic membrane using 5-aminolaevulinic acid. Hum Reprod 2000;15:584-588

108. Isachenko V, Isachenko $E$, Mallmann P, Rahimi G. Increasing follicular and stromal cell proliferation in cryopreserved human ovarian tissue after long-term precooling prior to freezing: in vitro versus chorioallantoic membrane (CAM) xenotransplantation. Cell Transplant 2013;22:2053-2061.

109. De Magalhães N, Liaw LH, Berns $\mathbf{M}$, et al. Applications of a new In vivo tumo spheroid based shell-less chorioallantoic membrane 3-D model in bioengineering research. J Biomed Sci Eng 2010:3:20-26.

110. Li M, Pathak RR, Lopez-Rivera E, et al. The in ovo chick chorioallantoic membrane (CAM) assay as an efficient xenograft model of hepatocellular carcinoma. $J$ Vis Exp 2015;104:e52411.

111. Nagchowdhuri PS, Andrews KN, Robart S, Capehart AA. Versican knockdown reduces interzone area during early stages of chick synovial joint development. Anat Rec (Hoboken) 2012;295:397-409.

112. Yalcin HC, Shekhar A, Rane AA, Butcher JT. An ex-ovo chicken embryo culture system suitable for imaging and microsurgery applications. J Vis Exp 2010;44:2154.

113. McKinney MC, Kulesa PM. In vivo calcium dynamics during neural crest cell migration and patterning using GCaMP3. Dev Bio/ 2011;358:309-317.

114. Xiao X, Zhou $X$, Ming H, et al. Chick chorioallantoic membrane assay: a $3 D$ animal model for study of human nasopharyngeal carcinoma. PLoS One 2015;10:e0130935.

115. Baiguera S, Macchiarini P, Ribatti D. Chorioallantoic membrane for in vivo investigation of tissue-engineered construct biocompatibility. J Biomed Mater Res B App/ Biomater 2012;100:1425-1434

116. Buschmann J, Härter $L$, Gao $S$, et al. Tissue engineered bone grafts based on biomimetic nanocomposite PLGA/amorphous calcium phosphate scaffold and human adipose-derived stem cells. Injury 2012;43:1689-1697.
117. Singh S, Wu BM, Dunn JC. Delivery of VEGF using collagen-coated polycaprol actone scaffolds stimulates angiogenesis. J Biomed Mater Res A 2012;100:720 727

118. Schomann T, Qunneis F, Widera D, Kaltschmidt C, Kaltschmidt B. Improved method for ex ovo-cultivation of developing chicken embryos for human stem cell xenografts. Stem Cells Int 2013;2013:960958.

119. Freed LE, Guilak F, Guo XE, et al. Advanced tools for tissue engineering: scaffolds, bioreactors, and signaling. Tissue Eng 2006;12:3285-3305.

120. Parikh MR, Belch AR, Pilarski LM, Kirshner J. A three-dimensional tissue culture model to study primary human bone marrow and its malignancies. J Vis Exp 2014:8.

121. Jaasma MJ, O'Brien FJ. Mechanical stimulation of osteoblasts using steady and dynamic fluid flow. Tissue Eng Part A 2008;14:1213-1223.

122. Batra NN, Li YJ, Yellowley CE, et al. Effects of short-term recovery periods on fluid-induced signaling in osteoblastic cells. J Biomech 2005;38:1909-1917.

123. Kreke MR, Huckle WR, Goldstein AS. Fluid flow stimulates expression of osteopontin and bone sialoprotein by bone marrow stromal cells in a temporally dependent manner. Bone 2005;36:1047-1055.

124. Birmingham E, Niebur GL, McHugh PE, et al. Osteogenic differentiation of mesenchymal stem cells is regulated by osteocyte and osteoblast cells in a simplified bone niche. Eur Cell Mater 2012;23:13-27.

125. Ortega N, Behonick DJ, Werb Z. Matrix remodeling during endochondral ossification. Trends Cell Biol 2004;14:86-93.

126. Dai J, Rabie ABM. VEGF: an essential mediator of both angiogenesis and endochondral ossification. J Dent Res 2007;86:937-950.

127. Mackie EJ, Ahmed YA, Tatarczuch L, Chen KS, Mirams M. Endochondral ossification: how cartilage is converted into bone in the developing skeleton. Int $J$ Biochem Cell Bio/ 2008;40:46-62.

128. Oldknow KJ, MacRae VE, Farquharson C. Endocrine role of bone: recent and emerging perspectives beyond osteocalcin. J Endocrinol 2015;225:R1-R19.

129. Vandoorne K, Magland J, Plaks V, et al. Bone vascularization and trabecular bone formation are mediated by PKB alpha/Akt1 in a gene-dosage-dependent manner: in vivo and ex vivo MRI. Magn Reson Med 2010;64:54-64

130. Marenzana M, Arnett TR. The key role of the blood supply to bone. Bone Res 2013:1:203-215

Funding Statement

This work was supported by a grant from the Ministry of Higher Education Malaysi (02-01-13-1200FR)

Author Contribution

A. A. Abubakar: Initial draft, Editing, Data analysis, Reviewing the paper.

M. M. Noordin: Reviewed and edited the paper.

- T. I. Azmi: Reviewed and edited the paper.

U. Kaka: Initial draft, Editing, Data analysis.

M. Y. Loqman: Initial concept, Participated in initial draft, Editing, Data analysis, Reviewing of the paper.

ICMJE conflict of interest

None declared

(ㄷ) 2016 Loqman et al. This is an open-access article distributed under the terms of the Creative Commons Attributions licence (CC-BY-NC), which permits unrestricted use, distribution, and reproduction in any medium, but not for commercial gain, provided the original author and source are credited. 